\title{
The dual glucose-dependent insulinotropic polypeptide (GIP) and glucagon-like peptide-1 (GLP-1) receptor agonist tirzepatide: a novel cardiometabolic therapeutic prospect
}

\author{
Enrique Z. Fisman * ${ }^{*}$ and Alexander Tenenbaum
}

\begin{abstract}
Incretin hormones are peptides released in the intestine in response to the presence of nutrients in its lumen. The main incretins are glucagon-like peptide-1 (GLP-1) and glucose-dependent insulinotropic polypeptide (GIP). GLP-1 stimulates insulin secretion, inhibits glucagon secretion at pancreatic a cells and has also extrapancreatic influences as slowing of gastric emptying which increases the feeling of satiety. GIP is the main incretin hormone in healthy people, causative of most the incretin effects, but the insulin response after GIP secretion in type 2 diabetes mellitus (T2DM) is strongly reduced. Therefore, in the past GIP has been considered an unappealing therapeutic target for T2DM. This conception has been changing during recent years, since it has been reported that resistance to GIP can be reversed and its effectiveness restored by improving glycemic control. This fact paved the way for the development of a GIP receptor agonist-based therapy for T2DM, looking also for the possibility of finding a combined GLP-1/GIP receptor agonist. In this framework, the novel dual GIP and GLP-1 receptor agonist tirzepatide seems to be not just a new antidiabetic medication. Administered as a subcutaneous weekly injection, it is a manifold single pharmacological agent that has the ability to significantly lower glucose levels, as well as improve insulin sensitivity, reduce weight and amend dyslipidemia favorably modifying the lipid profile. Tirzepatide and additional dual GLP-1/GIP receptor agonists that could eventually be developed in the future seem to be a promising furthest advance for the management of several cardiometabolic settings. Obviously, it is too early to be overly hopeful since it is still necessary to determine the long-term effects of these compounds and properly verify the potential cardiovascular benefits. Anyway, we are currently facing a novel and very appealing therapeutic option.
\end{abstract}

Keywords: Dual GLP-1/GIP receptor agonist, Glucagon-like peptide-1, Glucose-dependent insulinotropic polypeptide, Incretins, Obesity, Tirzepatide, Triglycerides, Type 2 diabetes mellitus

\section{Background}

Incretin hormones are peptides released in the intestine in response to the presence of nutrients in its lumen. The observation that the induced effect on insulin secretion is different when oral glucose was administered versus

*Correspondence: zfisman@tauex.tau.ac.il

Department of Cardiology, Sackler Faculty of Medicine, Tel Aviv University, 6997801 Ramat Aviv, Israel the same amount of glucose parenterally coined the term 'incretin effect', supporting the idea that some substances secreted in the intestines favored the release of insulin after ingestion [1]. This effect is part of the entero-insular axis of glucose homeostasis and is estimated to be responsible for at least $50 \%$ of insulin secretion $[2,3]$.

The main incretins are glucagon-like peptide-1 (GLP-1) and glucose-dependent insulinotropic polypeptide (GIP). GLP-1 is a 30 amino acid peptide produced by the $L$ cells, original author(s) and the source, provide a link to the Creative Commons licence, and indicate if changes were made. The images or other third party material in this article are included in the article's Creative Commons licence, unless indicated otherwise in a credit line to the material. If material is not included in the article's Creative Commons licence and your intended use is not permitted by statutory regulation or exceeds the permitted use, you will need to obtain permission directly from the copyright holder. To view a copy of this licence, visit http://creativecommons.org/licenses/by/4.0/. The Creative Commons Public Domain Dedication waiver (http://creativecommons.org/publicdomain/zero/1.0/) applies to the data made available in this article, unless otherwise stated in a credit line to the data. 
enteroendocrine cells of the distal ileum and colon, and GIP is a 4 amino acid peptide produced by the $\mathrm{K}$ cells of the duodenum and jejunum. Both hormones are rapidly released after ingestion, apparently under neural control, and stimulate insulin production in pancreatic $\beta$ cells in a glucose-dependent manner. Furthermore, GLP-1 decreases glucagon secretion from pancreatic $\alpha$ cells and has also extrapancreatic influences as a direct suppressive effect on appetite centers and a slowing of gastric emptying increasing the feeling of satiety. It has been shown that in patients with type 2 diabetes mellitus (T2DM) the response to the incretin effect is altered as a result of a severe defect in the sensitivity for GIP in the $\beta$ cells [4] and a reduction in food-induced GLP-1 secretion $[5,6]$.

Plasma concentrations of GLP-1 and GIP are very low in the fasting state and increase 15-30 min after ingestion. The incretin effect is very brief because it remains active 1-2 min after its secretion and is then inactivated by the enzyme dipeptidylpeptidase-4 (DPP-4) [7]. This very short action limited the initial enthusiasm for the possible usefulness of incretins for the treatment of T2DM, and in turn stimulated the development of both GLP1 agonists resistant to DPP-4, with a longer half-life and of DPP-4 inhibitors that prolong the half-life of native incretins. A large real world evidence demonstrated that when comparing several GLP-1 receptor agonists versus DPP-4 inhibitors treatments in patients with a baseline cardiovascular risk, the incidence of adverse events was much lower for the former [8]; the GLP-1 semaglutide reduced the risk of major adverse cardiovascular events vs comparators in a broad T2DM population [9].

It should be pinpointed that while GIP acts almost exclusively at the pancreatic $\beta$ level, there are widely distributed receptors for GLP-1 (R-GLP1) in the endocrine pancreas $(\alpha$ and $\beta)$, in heart, stomach, adipose tissue, vagus nerve and in various regions of the central nervous system. Animal studies have shown that GLP-1 promotes neogenesis and cell proliferation, inhibits apoptosis, and increases the mass of $\beta$ cells [6]. On the other hand, a series of positive effects have been described in pathways involved in vascular atherogenesis, endothelial function $[7,10]$ and ventricular contractility [11]. Thus, in addition to regulating glucose control, protective effects are attributed to this incretin at the insular, neural and cardiovascular level.

GIP is the main incretin hormone in healthy people, causative of most the incretin effects but the insulin response after GIP secretion in T2DM is reduced [12]. It has been reported that there is no reduction in its secretion in patients with T2DM [13] but a nearly total loss of insulinotropic effect is observed, even at supraphysiological concentrations, implying the existence of GIP resistance [14]. Therefore, in the past GIP has been considered an unappealing therapeutic target for T2DM. This conception has been changing during recent years, since it has been reported that resistance to GIP can be reversed and its effectiveness restored by improving glycemic control [14]. A potential additional advantage of GIP is the protection against hypoglycemia since GIP infusion is accompanied by a decreased need for further glucose administration to maintain a satisfactory glycemic level during an insulin-induced hypoglycemic clamp [15]. Moreover, it improves triglyceride clearance and the sensitivity of adipose tissue to insulin, which may prevent ectopic fat deposition [16]. These facts paved the way for the development of a GIP receptor agonist-based therapy for T2DM, looking also for the possibility of finding a dual GLP-1/GIP receptor agonist [17].

\section{A dual GLP-1/GIP receptor agonist}

An ideal antidiabetic medication should present proven efficacy in lowering elevated glucose levels, promote weight loss, have low risk of hypoglycemia and offer cardiovascular benefits [18]. The idea of simultaneously activating both the GIP and GLP-1 receptors seems appealing for treatment of T2DM since it may significantly boost insulin secretion and improve insulin sensitivity. The main physiological actions of such compound are depicted in Fig. 1; the rationale is based on the fact that improved glycemia restores sensitivity to GIP [14, 16] and peptide engineering enables the design of hybrid ligands exhibiting dual agonism, as proved in experimental studies [19].

Tirzepatide, the first dual GIP and GLP-1 receptor agonist, is in keeping with these conceptions. Its chemical formula is based on the GIP amino acid sequence and its half-life of approximately 5 days is compatible with a once-weekly subcutaneous administration. Chemically, tirzepatide is a synthetic linear peptide containing 39 aminoacids based on the native GIP sequence. This basic structure is accompanied by a 20-carbon fatty diacid moiety that prolongs its half-life. The mechanism of action is very imbalanced, since while it has a comparable GIP receptor binding affinity to native GIP, the affinity to the native GLP-1 receptor is five times lower [20, 21]. So, it is a bireceptor agonist, product of the above mentioned peptide engineering, created as a single agent possessing activity at more than one pharmacological target.

The drug was designed for once-weekly subcutaneous administration and early clinical investigation of tirzepatide demonstrated exceptional efficacy for glucose lowering and weight loss in T2DM. A phase 1 proof-of-concept clinical trial was conducted in 53 people with T2DM and translated the favorable preclinical data into clinical facts; the compound delivered clinically meaningful improvement in glycemic control and body weight warranting 


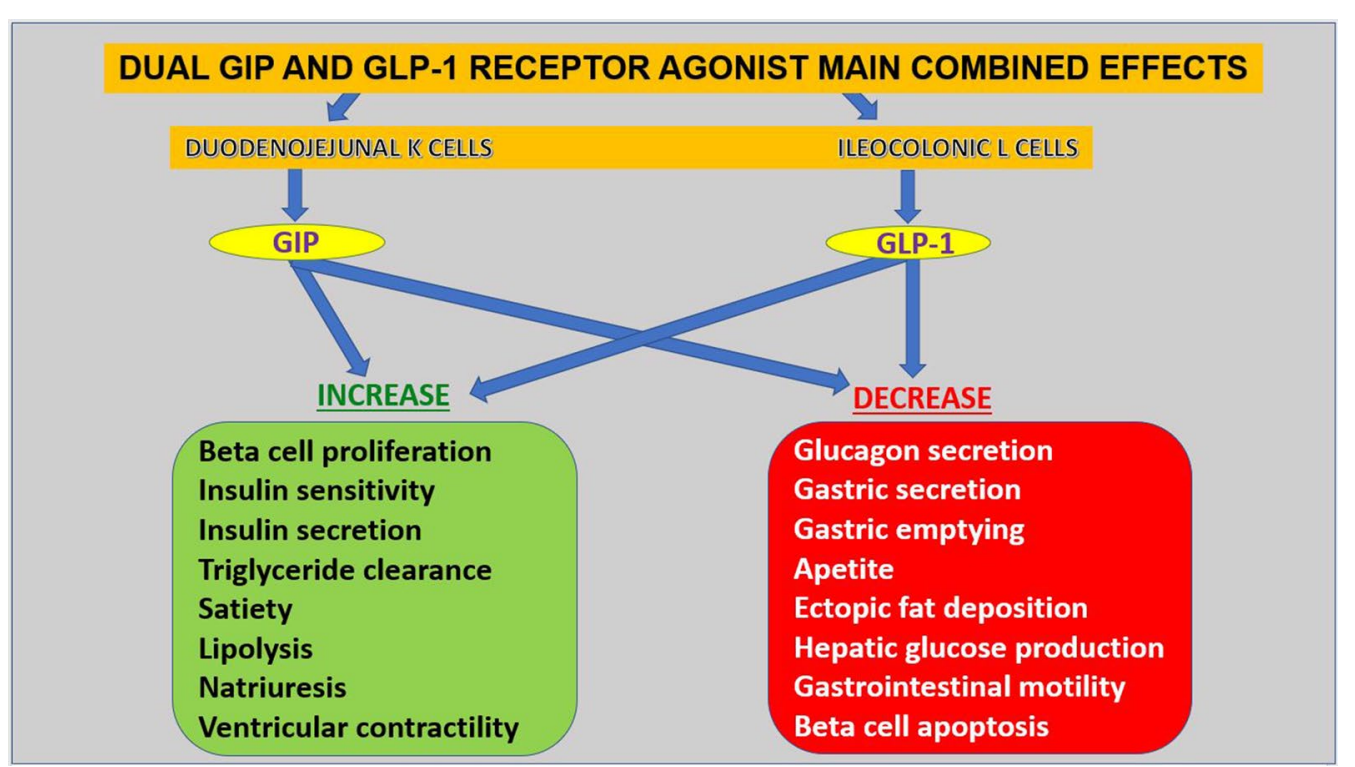

Fig. 1 Main physiological actions of the dual GIP and GLP-1 agonist tirzepatide. GIP_glucose-dependent insulinotropic polypeptide; GLP-1 — glucagon-like peptide-1. Despite the similarities between the two incretins, it should be pinpointed that while GIP activity is mainly pancreatic, GLP-1 activity is systemic

further clinical evaluation for the treatment of T2DM and obesity [21]. About $30 \%$ of patients receiving a $15 \mathrm{mg}$ dose reached normoglycemia with hemoglobin A1C $(\mathrm{HbA} 1 \mathrm{C})<5.7 \%$ and $25 \%$ of patients lost $\geq 15 \%$ of their body weight in a 26 -week phase $2 b$ trial $[22,23]$.

Compared to the GLP-1 agonist dulaglutide, tirzepatide reduced $\mathrm{HbA1C}$ by $1.6 \%, 2.0 \%$, and $2.4 \%$ in the 5,10 , and $15 \mathrm{mg}$ dose groups, respectively, compared with $1.1 \%$ only for dulaglutide $1.5 \mathrm{mg}$. Moreover, $8 \%$ of patients receiving $10 \mathrm{mg}$ and $30 \%$ dosed with $15 \mathrm{mg}$ reached normoglycemia $(\mathrm{HbA} 1 \mathrm{C}<5.7 \%)$ compared with $2 \%$ of subjects treated with dulaglutide. Tirzepatide at $5 \mathrm{mg}$ and $10 \mathrm{mg}$ provided superior glycemic and bodyweight control versus dulaglutide, presenting similar tolerability [22]. These beneficial effects were confirmed in the SURPASS-1 study, the first randomized controlled phase 3 trial of tirzepatide. Study participants had a mean duration of diabetes of 4.7 years, a baseline A1C of $7.9 \%$ and a baseline weight of $85.9 \mathrm{~kg}$. Nearly $90 \%$ of all participants taking tirzepatide achieved the standard HbA1C goal of $>7 \%$ and more than half taking the highest of the three doses also achieved an $\mathrm{HbA1C}>5.7 \%$, a level observable in people without diabetes. No events of severe hypoglycemia $(<54 \mathrm{mg} / \mathrm{dL})$ were observed. Regarding collateral effects, the most commonly reported were gastrointestinal-related (diarrhea, nausea, vomiting, constipation) mainly occurring during the dose escalation period. Thus, these results showed a strong glucoselowering effects towards a nearly-normal range with weight loss of a not previously reported extent in people with T2DM and without increased risk of clinically significant hypoglycemia [24].

The recently published SURPASS-2 has been conducted in order to compare the efficacy and safety of the three doses of tirzepatide with the GLP-1 agonist semaglutide at an injectable dose of $1 \mathrm{mg}$ in patients with T2DM inadequately controlled with metformin monotherapy; it has been performed in an open-label, 40-week, phase 3 trial [25]. All three tirzepatide doses achieved greater $\mathrm{A} 1 \mathrm{C}$ and weight reductions compared to semaglutide. In addition, a composite endpoint comprised of participants who achieved an $\mathrm{HbA} 1 \mathrm{C}$ level $\geq 6.5 \%$ and weight loss of at least $10 \%$, was assessed. Across the three doses of tirzepatide, all patients achieved this composite endpoint in a significantly greater percent compared to patients on semaglutide, with a satisfactory safety profile [25].

\section{Effects on lipid profile}

T2DM patients have usually atherogenic dyslipidemia, depicted by high triglycerides and low-density lipoprotein cholesterol (LDL-C) levels, accompanied by low levels of high-density lipoprotein cholesterol (HDL-C). The upsurge of very-low-density lipoprotein particles seems to be the core atherogenic dyslipidemia in T2DM, which is partially secondary to insulin resistance [26]. In a study aimed to establish tirzepatde influence on lipid profile [27], at 26 weeks the three dosages of the drug decreased 
the levels of apoB, apoC-III levels, large triglyceride-rich lipoprotein particles, and small low-density lipoprotein particles compared with both placebo and dulaglutide. Patients with high baseline triglycerides $(\geq 150 \mathrm{mg} / \mathrm{dL})$ levels showed a relatively greater reduction in apoC-III compared with those presenting normal levels. The dosedependent decrease in apoC-III seems to partially explain the reduction in triglycerides following tirzepatide treatment, independently of weight loss. A net improvement in insulin sensitivity and a dose-dependent increase in preheparin plasma levels were also observed [27].

\section{A novel cardiometabolic therapeutic prospect}

Cardiometabolic diseases as diabetes mellitus, heart disease, overweight, obesity, hypertension, hyperlipidemia and its multiple macro and microvascular complications (ischemic cardiomyopathy, stroke, chronic kidney disease, retinopathy, peripheral neuropathy, etc.) are conditions closely related to each other and constitute at present time the leading cause of morbility, disability and death in the world [28].

The molecular and cellular alterations that lead to these diseases begin many years before clinical manifestations become apparent. The development of a manifold single pharmacological agent like tirzepatide that has the ability to significantly lower glucose levels, as well as improve insulin sensitivity, reduce weight and amend dyslipidemia at an early clinical stage is enormously important. Therefore, this compound seems to be not solely a new antidiabetic medication. Tirzepatide, administered as a weekly subcutaneous injection, and additional dual GLP-1/GIP receptor agonists that could eventually be developed in the future seem to be a promising furthest advance for the management of several cardiometabolic settings. Obviously, it is too early to be overly hopeful since it is still necessary to determine the long-term effects of these compounds and properly verify the potential cardiovascular benefits. Anyway, we are currently facing a novel and very appealing therapeutic option.

\section{Abbreviations}

DPP-4: Dipeptidylpeptidase-4; GIP: Glucose-dependent insulinotropic polypeptide; GLP-1: Glucagon-like peptide-1; HbA1C: Hemoglobin A1C; HDL-C: High-density lipoprotein cholesterol; LDL-C: Low-density lipoprotein cholesterol; T2DM: Type 2 diabetes mellitus.

\section{Acknowledgements}

Not applicable.

\section{Authors' contributions}

Both authors contributed equally to this manuscript. Both authors read and approved the final manuscript.

\section{Funding}

Not applicable.
Availability of data and materials

Not applicable.

\section{Declarations}

Ethics approval and consent to participate

Not applicable.

\section{Consent for publication \\ Not applicable.}

\section{Competing interests}

The authors declare that there is no conflict of interest.

Received: 8 October 2021 Accepted: 31 October 2021

Published online: 24 November 2021

\section{References}

1. Elrick H, Stimmler L, Hlad CJ, Arai Y. Plasma insulin response to oral and intravenous glucose administration. J Clin Endocrinol Metab. 1964;24:1076-82.

2. Nauck MA, Homberger E, Siegel EG, Allen RC, Eaton RP, Ebert R, Creutzfeldt W. Incretin effects of increasing glucose loads in man calculated from venous insulin and C-peptide responses. J Clin Endocrinol Metab. 1986;63:492-8.

3. Creutzfeldt W. The incretin concept today. Diabetologia. 1979;16:75-85.

4. Nauck MA, Stockmanne F, Ebert R, Creutzfeldt W. Reduced incretin effect in type 2 (non-insulin-dependent) diabetes. Diabetologia. 1986;29:46-52.

5. Nauck MA, Heimesaat MM, Orskov C, Holst JJ, Ebert R, Creutzfeldt W. Preserved incretin activity of glucagon-like peptide 1[7-36 amide] but not of synthetic human gastric inhibitory polypeptide in patients with type-2 diabetes mellitus. J Clin Invest. 1993;91:301-7.

6. Abu-Hamdah R, Rabiee A, Meneilly GS, Shannon RP, Andersen DK, Elahi D. The extrapancreatic effects of glucagon-like peptide-1 and related peptides. J Clin Endocrinol Metab. 2009;94:1843-52.

7. Baggio LL, Drucker DJ. Biology of incretins: GLP-1 and GIP. Gastroenterology. 2007;132:2131-57.

8. Longato E, Di Camillo B, Sparacino G, Tramontan L, Avogaro A, Fadini GP. Better cardiovascular outcomes of type 2 diabetic patients treated with GLP-1 receptor agonists versus DPP-4 inhibitors in clinical practice. Cardiovasc Diabetol. 2020;19:74.

9. Husain M, Bain SC, Holst AG, Mark T, Rasmussen S, Lingvay I. Effects of semaglutide on risk of cardiovascular events across a continuum of cardiovascular risk: combined post hoc analysis of the SUSTAIN and PIONEER trials. Cardiovasc Diabetol. 2020;19:156.

10. Nystrom T, Gutniak MK, Zhang Q, Zhang F, Holst JJ, Ahrén B, Sjöholm A. Effects of glucagon-like peptide-1 on endothelial function in type 2 diabetes patients with stable coronary artery disease. Am J Physiol Endocrinol Metab. 2004;287:E1209-15.

11. Sokos GG, Nikolaidis LA, Mankad SD, Elahi E, Shannon RP. Glucagonlike peptide-1 infusion improves left ventricular ejection fraction and functional status in patients with chronic heart failure. J Card Fail. 2006;12:694-9.

12. Gasbjerg LS, Helsted MM, Hartmann B, Jensen MH, Gabe MBN, SparreUlrich AH, Veedfald S, Stensen S, Lanng AR, Bergmann NC, Christensen MB, Vilsbø\|I, Holst JJ, Rosenkilde MM, Knop FK. Separate and combined glucometabolic effects of endogenous glucose-dependent insulinotropic polypeptide and glucagon-like peptide 1 in healthy individuals. Diabetes. 2019:68:906-17.

13. Holst JJ, Windelov JA, Boer GA, Pedersen J, Svendsen B, Christensen M, Torekov S, Asmar M, Hartmann B, Nissen A. Searching for the physiological role of glucose-dependent insulinotropic polypeptide. J Diabetes Investig. 2016;7(Suppl 1):8-12.

14. Hojberg PV, Vilsboll T, Rabol R, Knop FK, Bache M, Krarup T, Holst JJ, Madsbad S. Four weeks of near-normalisation of blood glucose improves the insulin response to glucagon-like peptide-1 and glucose-dependent 
insulinotropic polypeptide in patients with type 2 diabetes. Diabetologia. 2009;52:199-207.

15. Christensen M, Vedtofte L, Holst JJ, Vilsboll T, Knop FK. Glucose-dependent insulinotropic polypeptide: a bifunctional glucose-dependent regulator of glucagon and insulin secretion in humans. Diabetes. 2011;60:3103-9.

16. Samms RJ, Coghlan MP, Sloop KW. How may GIP enhance the therapeutic efficacy of GLP-1? Trends Endocrinol Metab. 2020;31:410-21.

17. Pocai A, Carrington PE, Adams JR, Wright M, Eiermann G, Zhu L, Du X, Petrov A, Lassman ME, Jiang G, Liu F, Miller C, Tota LM, Zhou G, Zhang X, Sountis MM, Santoprete A, Capito E, Chicchi GG, Thornberry N, Bianchi E, Pessi A, Marsh DJ, Sinha RR. Glucagon-like peptide 1/glucagon receptor dual agonism reverses obesity in mice. Diabetes. 2009;58:2258-66.

18. Calanna S, Christensen M, Holst JJ, Laferrère B, Gluud LL, Vilsbøll T, Knop FK. Secretion of glucose-dependent insulinotropic polypeptide in patients with type 2 diabetes: systematic review and meta-analysis of clinical studies. Diabetes Care. 2013;36:3346-52.

19. Min T, Bain SC. The role of tirzepatide, dual GIP and GLP-1 receptor agonist, in the management of type 2 diabetes: the SURPASS clinical trials. Diabetes Ther. 2021:12:143-57.

20. Coskun T, Sloop KW, Loghin C, Alsina-Fernandez J, Urva S, Bokvist KB, Cui X, Briere DA, Cabrera O, Roell WC, Kuchibhotla U, Moyers JS, Benson CT, Gimeno RE, D'Alessio DA, Haupt A. LY3298176, a novel dual GIP and GLP-1 receptor agonist for the treatment of type 2 diabetes mellitus: from discovery to clinical proof of concept. Mol Metab. 2018;18:3-14.

21. Willard FS, Douros JD, Gabe MB, Showalter AD, Wainscott DB, Suter TM, Capozzi ME, van der Velden WJ, Stutsman C, Cardona GR, Urva S, Emmerson PJ, Holst JJ, D'Alessio DA, Coghlan MP, Rosenkilde MM, Campbell JE, Sloop KW. Tirzepatide is an imbalanced and biased dual GIP and GLP-1 receptor agonist. JCI Insight. 2020;5:e140532.

22. Frias JP, Nauck MA, Van J, Kutner ME, Cui X, Benson C, Urva S, Gimeno RE, Milicevic Z, Robins D, Haupt A. Efficacy and safety of LY3298176, a novel dual GIP and GLP-1 receptor agonist, in patients with type 2 diabetes: a randomised, placebo-controlled and active comparator-controlled phase 2 trial. Lancet. 2018;392(10160):2180-93.

23. Frias JP, Nauck MA, Van J, Benson C, Bray R, Cui X, Milicevic Z, Urva S, Haupt A, Robins DA. Efficacy and tolerability of tirzepatide, a dual glucose-dependent insulinotropic peptide and glucagon-like peptide-1 receptor agonist in patients with type 2 diabetes: A 12-week, randomized, double-blind, placebo-controlled study to evaluate different dose-escalation regimens. Diabetes Obes Metab. 2020;22:938-9462.

24. Rosenstock J, Wysham C, Frías JP, Kaneko S, Lee CJ, Fernández Landó L, Mao H, Cui X, Karanikas CA, Thieu VT. Efficacy and safety of a novel dual GIP and GLP-1 receptor agonist tirzepatide in patients with type 2 diabetes (SURPASS-1): a double-blind, randomised, phase 3 trial. Lancet. 2021;398(10295):143-55.

25. Frías JP, Davies MJ, Rosenstock J, Pérez Manghi FC, Fernández Landó L, Bergman BK, Liu B, Cui X, Brown K, for the SURPASS-2 Investigators. Tirzepatide versus semaglutide once weekly in patients with type 2 diabetes. N Engl J Med. 2021;385:503-15.

26. Ruotolo G, Howard BV. Dyslipidemia of the metabolic syndrome. Curr Cardiol Rep. 2002;4:494-500.

27. Wilson JM, Nikooienejad A, Robins DA, Roell WC, Riesmeyer JS, Haupt A, Duffin KL, Taskinen MR, Ruotolo G. The dual glucose-dependent insulinotropic peptide and glucagon-like peptide-1 receptor agonist, tirzepatide, improves lipoprotein biomarkers associated with insulin resistance and cardiovascular risk in patients with type 2 diabetes. Diabetes Obes Metab. 2020;22:2451-9.

28. Ralston J, Nugent R. Toward a broader response to cardiometabolic disease. Nat Med. 2019:25:644-1646.

\section{Publisher's Note}

Springer Nature remains neutral with regard to jurisdictional claims in published maps and institutional affiliations.
Ready to submit your research? Choose BMC and benefit from:

- fast, convenient online submission

- thorough peer review by experienced researchers in your field

- rapid publication on acceptance

- support for research data, including large and complex data types

- gold Open Access which fosters wider collaboration and increased citations

- maximum visibility for your research: over $100 \mathrm{M}$ website views per year

At BMC, research is always in progress.

Learn more biomedcentral.com/submissions 